\title{
Impact of nutritional screening index on perioperative morbidity after colorectal cancer surgery as a independent predictive factor
}

\author{
Yoon Hyung Kang ${ }^{1}$, Ji Won Park ${ }^{1,2,3}$, Seung Bum Ryoo' ${ }^{1}$, Seung Yong Jeong ${ }^{1,2,3}$, Kyu Joo Park \\ 'Department of Surgery, Seoul National University Hospital and College of Medicine, Seoul; \\ ${ }^{2}$ Cancer Research Institute, Seoul National University, Seoul; \\ ${ }^{3}$ Colorectal Cancer Center, Seoul National University Cancer Hospital, Seoul National University College of Medicine, Seoul, Korea
}

Purpose: Nutrition status is an important factor for perioperative morbidity in cancer surgery. The aim of this study was to evaluate the impact of the malnutrition risk, determined by Seoul National University Hospital-nutrition screening index (SNUH-NSI), on operative morbidity after colorectal surgery for cancer.

Methods: This study enrolled 2,462 patients who had undergone colectomy for initially diagnosed colorectal cancer at Seoul National University Hospital from January 2011 to December 2014. We collected general patient information, SNUH-NSI and prognostic nutritional index (PNI) at administration and related parameters (serum albumin, cholesterol, total lymphocyte counts, hemoglobin and body mass index), operative method, hospital stay and operative morbidity.

Results: Patients' mean age was 62.12 years, and 423 patients (17.18\%) were rated as severe malnutrition risk. Patients with high risk of malnutrition by SNUH-NSI or PNI, men, higher American Society of Anesthesiologists (ASA) class, palliative operation, and higher stage showed higher operative morbidity $(\mathrm{P}<0.05)$. On multivariate analysis, significant independent risk factors for operative morbidity were severe malnutrition by SNUH-NSI (odds ratio [OR], 1.868; 95\% confidence interval [CI], 1.429-2.442; $\mathrm{P}<0.001)$ or $\mathrm{PNI}(\mathrm{OR}, 1.596 ; 95 \% \mathrm{Cl}$, $1.258-2.025 ; \mathrm{P}<0.001)$, men $(\mathrm{OR}, 1.483 ; 95 \% \mathrm{Cl}, 1.174-1.876 ; \mathrm{P}=0.001)$, or high $\mathrm{ASA}$ class $(\mathrm{OR}, 1.782 ; 95 \% \mathrm{Cl}, 1.136-2.795 ; \mathrm{P}=0.012)$.

Conclusion: Overall nutritional status, rather than single data, shows significant association with postoperative morbidity in patients who underwent colectomy. Especially severe malnutrition determined by SNUH-NSI, is an independent risk factor for perioperative morbidity. Nutritional support to severely malnourished patient by SNUH-NSI is expected to be effective in preventing complications after colectomy of colorectal carcinoma patients.

Keywords: Colorectal cancer, Colectomy, Malnutrition, Screening, Morbidity

\section{INTRODUCTION}

Colorectal cancer is the third most commonly occurring cancer in the world, and its incidence is gradually increasing [1]. Despite advances in treatment methods, the rates of recurrence and mortality from colorectal cancer remain high [2]. Surgery is an important

Received: Oct 1, 2017 Accepted: Dec 13, 2017

Correspondence to: Ji Won Park

Department of Surgery, Seoul National University Hospital and College of Medicine, 101 Daehak-ro, Jongno-gu, Seoul 03080, Korea

Tel: +82-2-2072-2325, Fax: +82-2-766-3975

E-mail: sowisdom@gmail.com

Copyright (C) Korean Society of Surgical Oncology

This is an Open Access article distributed under the terms of the Creative Commons Attribution Non-Commercial License (http://creativecommons.org/licenses/by-nc/4.0) which permits unrestricted non-commercial use, distribution, and reproduction in any medium, provided the original work is properly cited. treatment method, but it may lead to surgical complications, which are associated with poor patient prognosis. The identification of factors predictive of complications can result in better patient prognosis.

Cancer patients are more likely to be malnourished than patients with other diseases [3], and association between preoperative nutrition and surgical outcome has been reported [4]. Malnutrition can delay treatment; increase infection, complication, and mortality rates; and prolong duration of hospital stay, leading to increased medical costs [5]. Since surgery may have major effects on treatment outcomes, surgical outcomes may be impred by investigating nutritional and immune status.

The 2006 the European Society of Parenteral and Enteral Nutrition guidelines suggest that patients undergoing upper gastrointestinal surgery who are at risk of severe malnutrition require preop- 
erative nutritional support, even if surgery is delayed [6]. These guidelines, however, do not provide recommendations for colorectal cancer patients, and few studies have described the association between nutritional status and postoperative outcomes in patients with colorectal cancer.

Various preoperative nutrition screening tools have been developed [4,7-11]. The prognostic nutritional index (PNI) is commonly used, with many studies showing that the PNI is a significant in- dicator of postoperative outcomes [4,7-11]. In addition, malnutrition risk, as determined by the Seoul National University Hospital-nutrition screening index (SNUH-NSI), was found to have a significant impact on postoperative complications in patients with gastric cancer [12].

The present study was designed to evaluate the risk of malnutrition at admission, as determined using nutrition screening tools, in patients undergoing colectomy for colorectal cancer, and to inves-

Table 1. Seoul National University Hospital-nutrition screening index (SNUH-NSI)

\begin{tabular}{lccc}
\hline Variables & $\mathrm{r1}$ & $\mathrm{r2}$ & $\mathrm{r}$ \\
\hline Appetite & Normal/Good & - & Bad \\
Change of weight & No & - & Yes \\
Difficulty in digesting & No & Yes & - \\
Diet type & Normal regular diet & Soft blended diet & Fluid diet \\
Serum-albumin & $\geq 3.3$ & $\geq 2.8,<3.3$ & $<2.8$ \\
Serum-cholesterol & $\geq 130$ & $<130$ & - \\
Total lymphocyte count & $\geq 1,500$ & $\geq 800,<1,500$ & $<800$ \\
Hemoglobin & $\geq 13.0$ & $<13.0$ & - \\
Male & $\geq 12.0$ & $<12.0$ & - \\
Female & $\leq 1$ & $>1$ & - \\
C-reactive protein & $\geq 18,<25$ & $<18$ or $\geq 25$ & - \\
Body mass index $\left(\mathrm{kg} / \mathrm{m}^{2}\right)$ & $\leq 75$ & $>75$ & - \\
Age $(\mathrm{yr})$ & & & - \\
\hline
\end{tabular}

High risk group, (more than 2 of $r 3$ ) or (1 of $r 3+$ more than 2 of $r 2$ ); Low risk group, the others. r, risk factor.

Table 2. Definition of complications

\begin{tabular}{lll}
\hline Group & \multicolumn{1}{c}{ Classification } & \multicolumn{1}{c}{ Definition } \\
\hline Wound complication & Wound infection & Re-suture (wound repair) or delay in discharge \\
$\begin{array}{l}\text { Operation related } \\
\text { complication }\end{array}$ & Intraabdominal fluid collection/abscess & Confirmed by CT, NPO or PCD required \\
& Intraabdominal bleeding & Transfusion or intervention (angiography, reoperation) required \\
Intraluminal bleeding & Transfusion or intervention required \\
& Intestinal obstruction & Obstruction point (+), NPO or reoperation required, re-admission or ER visit \\
& (weus & (within 30 days) \\
& Anastomosis stenosis & Obstruction point (-), delay in discharge due to NPO \\
& Anastomosis leakage & Confirmed by colonoscopy or colon study, intervention required \\
& Pancreatitis & Confirmed by fistulogram \\
& Enterocutaneous fistula & Confirmed by CT, delay in discharge due to NPO \\
Lymphatic leakage & Confirmed by fistulogram \\
Stoma complication & Chylous drainage via Jackson-Pratt drainage, NPO or low fat diet required \\
Pulmonary & Prolapse, necrosis, bleeding, retraction \\
Renal/urinary & Pleural effusion, pneumonia \\
Hepatic & Urinary tract infection, acute renal failure \\
Cardiac & Liver abscess, liver failure \\
Endocrine & Myocardial infarction, heart infarction, arrhythmia \\
& Diabetes Insipidus, diabetic ketoacidosis, syndrome of inappropriate secretion of \\
Neurologic & antidiuretic hormone \\
Thromboembolism & Delirium, cognitive disorder, psychosis \\
& Deep vein thromboembolism, pulmonary thromboembolism \\
\hline
\end{tabular}

$\mathrm{CT}$, computed tomography; NPO, nil per os (nothing by month); PCD, percutaneous drainage; ER, emergency room. 
tigate the effects of preoperative malnutrition on the occurrence of postoperative complications.

\section{METHODS}

This retrospective study evaluated 3,746 patients who were admitted to Seoul National University Hospital (SNUH) for primary colorectal cancer and who underwent colectomy from January
2011 to December 2014. Patients with a history of other cancers, recurrent colorectal cancer, or hereditary colorectal cancer; and patients who underwent combined resection of other organs or had insufficient data for analysis were excluded from this study. The study cohort consisted of 2,462 patients, with patient data retrospectively collected from electronic medical records. The study protocol was approved by the Institutional Review Board of SNUH (IRB no. H-1712-043-905).

Table 3. General characteristics of the subjects

\begin{tabular}{|c|c|c|c|c|}
\hline \multirow{2}{*}{ Variable } & \multirow{2}{*}{ Total $(n=2,462)$} & \multicolumn{3}{|c|}{ SNUH-NSI } \\
\hline & & High risk group $(n=423)$ & Low risk group $(n=2,039)$ & P-value \\
\hline Age (yr) & $62.12 \pm 11.25$ & $64.22 \pm 12.12$ & $61.84 \pm 11.01$ & $<0.001$ \\
\hline$<60$ & 996 (40.45) & 145 (34.28) & 851 (41.74) & 0.004 \\
\hline$\geq 60$ & $1,466(59.55)$ & $278(65.72)$ & $1,188(58.26)$ & \\
\hline Sex & & & & 0.851 \\
\hline Male & $1,500(60.93)$ & $256(60.52)$ & 1,244 (61.01) & \\
\hline Female & $962(39.07)$ & $167(39.48)$ & 795 (38.99) & \\
\hline ASA classification & & & & $<0.001$ \\
\hline 1 & $938(38.10)$ & $129(30.50)$ & 809 (39.68) & \\
\hline 2 & $1,420(57.68)$ & $255(60.28)$ & $1,165(57.14)$ & \\
\hline 3 & $103(4.18)$ & $38(8.98)$ & $65(3.19)$ & \\
\hline 4 & $1(0.04)$ & $1(0.24)$ & $0(0.0)$ & \\
\hline Body mass index $\left(\mathrm{kg} / \mathrm{m}^{2}\right)$ & $23.38 \pm 3.36$ & $22.39 \pm 3.66$ & $23.58 \pm 3.216$ & $<0.001$ \\
\hline$<18.5$ & 145 (5.89) & 59 (13.95) & $86(4.22)$ & \\
\hline$\geq 18.5,<23$ & $1,030(41.84)$ & $202(47.75)$ & $828(40.61)$ & \\
\hline$\geq 23,<25$ & $580(23.56)$ & 71 (16.78) & 509 (24.96) & \\
\hline$\geq 25$ & 707 (28.72) & $91(21.51)$ & $616(30.21)$ & \\
\hline Smoking & & & & 0.727 \\
\hline No & 1,946 (79.04) & 337 (79.67) & 1,609 (78.91) & \\
\hline Yes & $516(20.96)$ & $86(20.33)$ & $430(21.09)$ & \\
\hline Alcohol intake & & & & 0.040 \\
\hline No & 1,707 (69.33) & 311 (73.52) & $1,396(68.46)$ & \\
\hline Yes & 755 (30.67) & $112(26.48)$ & $643(31.54)$ & \\
\hline Stage & & & & $<0.001$ \\
\hline $0-1$ & $512(20.80)$ & 45 (10.64) & $467(22.90)$ & \\
\hline 2 & $703(28.55)$ & $124(29.31)$ & $579(28.40)$ & \\
\hline 3 & 868 (35.26) & $132(31.21)$ & $736(36.10)$ & \\
\hline 4 & 379 (15.39) & $122(28.84)$ & $257(12.60)$ & \\
\hline Curative/Palliative surgery & & & & $<0.001$ \\
\hline Curative & 2,251 (91.47) & $328(77.73)$ & $1,923(94.31)$ & \\
\hline Palliative & $210(8.53)$ & $94(22.27)$ & $116(5.69)$ & \\
\hline Surgical approach & & & & $<0.001$ \\
\hline Open & $1,743(70.80)$ & 337 (79.67) & $1,406(68.96)$ & \\
\hline Laparoscopic & 719 (29.20) & $86(20.33)$ & $633(31.04)$ & \\
\hline Tumor location & & & & $<0.001$ \\
\hline Colon & 799 (32.45) & 173 (40.90) & $626(30.70)$ & \\
\hline Rectosigmoid & $1,658(67.34)$ & 247 (58.39) & $1,411(69.20)$ & \\
\hline Both & $5(0.2)$ & $3(0.6)$ & $2(0.1)$ & \\
\hline Hospital stay (day) & $7.94 \pm 5.07$ & $9.85 \pm 6.99$ & $7.55 \pm 4.47$ & $<0.001$ \\
\hline
\end{tabular}

Values are presented as mean \pm standard deviation or number (\%).

SNUH-NSI, Seoul National University Hospital-nutrition screening index; ASA, American Society of Anesthesiologists. 


\section{Nutrition screening tools}

The risk of malnutrition in patients was assessed within 24 hours of admission using the SNUH-NSI. The SNUH-NSI was determined from parameters such as age, body mass index (BMI), changes in weight, appetite, digestive disorders, and meal pattern at admission. Other factors included in the SNUH-NSI were serum albumin, total cholesterol level, and C-reactive protein (CRP) concentrations; total lymphocyte count; and hemoglobin level measured within 2 weeks before admission. Based on these parameters, the risk of malnutrition was classified as r1, r2, and r3 [13-16], with the patients classified into a high-risk group and a low-risk group for malnutrition (Table 1).

Nutrition status was also classified using the PNI, a widely used nutrition screening tool. The PNI was calculated using the formula: albumin concentration $(\mathrm{g} / \mathrm{dL}) \times 10+$ total lymphocyte count $\times$ $0.005\left(/ \mathrm{mm}^{3}\right)$.

\section{Patient data}

Baseline demographic and clinical information collected from patients' electronic medical records included age, sex, American Society of Anesthesiologists (ASA) classification, smoking status, history of alcohol intake, clinical stage, radical or palliative surgery, operative methods, tumor location, presence or absence of postoperative complications, and nutritional risk group. The postoperative complications were classified as shown in Table 2.

\section{Statistical analysis}

General characteristics and anthropometric factors were expressed as mean \pm standard deviation, and its number and percentage was counted. Continuous variables were compared using t-tests and analysis of variance test, and categorical variables were compared using chi-square tests. Multivariate logistic regression analysis was performed to analyze factors independently predictive of the risk of complications. Statistical significance was defined as a P-value $<0.05$. All statistical analyses were performed using SPSS ver. 22.0 K for Windows (IBM Corp., Somers, NY, USA).

\section{RESULTS}

\section{General characteristics of the subjects}

The demographic and clinical characteristics of the 2,462 patients in the study population are shown in Table 3. Preoperative nutritional screening showed that 423 patients (17.18\%) were in the high-risk group for malnutrition and 2,039 (82.82\%) were in the low-risk group for malnutrition according to SNUH-NSI scores. The mean age of all patients was $62.12 \pm 11.25$ years, and was significantly higher in the group at high than at low risk for malnutrition $(64.22 \pm 12.12$ vs. $61.84 \pm 11.01$ years, $\mathrm{P}<0.001)$. The mean postoperative length of stay was $7.94 \pm 5.07$ days and was significantly longer in the group at high than at low risk for malnutrition $(9.85 \pm 6.99$ vs. $7.55 \pm 4.47$ days, $\mathrm{P}<0.001)$. The mean BMI was $23.38 \pm 3.36 \mathrm{~kg} / \mathrm{m}^{2}$, with $145(5.89 \%)$ patients having a BMI $<18.5$

Table 4. Incidence of postoperative morbidity $(\mathrm{P}<0.001)$

\begin{tabular}{|c|c|c|c|}
\hline Complication & High risk group $(n=423)$ & Low risk group $(n=2,039)$ & Total $(n=2,462)$ \\
\hline Wound infection & $14(3.3)$ & $32(1.6)$ & $46(1.9)$ \\
\hline Intraabdominal fluid collection/abscess & $4(0.9)$ & $8(0.4)$ & $12(0.5)$ \\
\hline Intraabdominal bleeding & $1(0.2)$ & 0 & $1(<0.1)$ \\
\hline Intestinal obstruction & 0 & 0 & 0 \\
\hline lleus & $7(1.7)$ & $36(1.8)$ & $43(1.7)$ \\
\hline Stenosis & $9(2.1)$ & $24(1.2)$ & $33(1.3)$ \\
\hline Anastomotic leakage & 0 & $3(0.1)$ & $3(0.1)$ \\
\hline Enterocutaneous fistula & 0 & $2(0.1)$ & $2(0.1)$ \\
\hline Lymphatic leakage & $3(0.7)$ & $15(0.7)$ & $18(0.7)$ \\
\hline Stoma & 0 & $2(0.1)$ & $2(0.1)$ \\
\hline Pancreatitis & 0 & 0 & $1(0.03)$ \\
\hline Pulmonary & $9(2.1)$ & $16(0.8)$ & $25(1.0)$ \\
\hline Renal/Urinary & $2(0.5)$ & $18(0.9)$ & $20(0.8)$ \\
\hline Cardiac & $1(0.2)$ & $3(0.1)$ & $4(0.2)$ \\
\hline Hepatic dysfuction & 0 & 0 & 0 \\
\hline Neurologic & $1(0.2)$ & $3(0.1)$ & $4(0.2)$ \\
\hline Thromboembolism & 0 & $1(<0.1)$ & $1(<0.1)$ \\
\hline Mutliple & $57(13.5)$ & $121(5.9)$ & $178(7.2)$ \\
\hline Total & $108(25.5)$ & 283 (13.9) & 391 (15.9) \\
\hline
\end{tabular}


$\mathrm{kg} / \mathrm{m}^{2}$ and $707(28.72 \%)$ having a BMI $\geq 25 \mathrm{~kg} / \mathrm{m}^{2}$.

Of the 2,462 patients in the study cohort, 1,247 (50.65\%) had stages 3 and 4 colorectal cancer, 1,658 (67.34\%) had cancers in the rectum and sigmoid colon and 1,743 (70.80\%) underwent open surgery. The risk of malnutrition did not differ according to sex or smoking status, but differed significantly according to age, ASA class, BMI, drinking status, clinical stage, radical resection, operative method, and tumor location $(\mathrm{P}<0.05$ each).

\section{Postoperative complications}

Of the 2,462 patients, 391 (15.9\%) experienced postoperative com-

Table 5. Univariate analysis of risk factors for postoperative morbidity

\begin{tabular}{|c|c|c|c|}
\hline Variable & $\begin{array}{l}\text { No. of } \\
\text { patients }\end{array}$ & $\begin{array}{c}\text { No. with } \\
\text { complications (\%) }\end{array}$ & P-value \\
\hline Sex & & & 0.001 \\
\hline Male & 1,500 & 269 (17.9) & \\
\hline Female & 962 & $122(12.7)$ & \\
\hline ASA class & & & $<0.001$ \\
\hline 1,2 & 2,358 & $360(15.3)$ & \\
\hline 3,4 & 104 & 31 (29.8) & \\
\hline Smoking & & & 0.275 \\
\hline No & 1,946 & 301 (15.5) & \\
\hline Yes & 516 & $90(17.4)$ & \\
\hline Alcohol & & & 0.710 \\
\hline No & 1,707 & $256(15.0)$ & \\
\hline Yes & 755 & $135(17.9)$ & \\
\hline Curative/Palliative surgery & & & 0.004 \\
\hline Curative & 2,251 & $343(15.2)$ & \\
\hline Palliative & 210 & $48(22.9)$ & \\
\hline SNUH-NSI & & & $<0.001$ \\
\hline Low risk group & 2,039 & $279(13.7)$ & \\
\hline High risk group & 423 & $112(26.5)$ & \\
\hline PNI & & & $<0.001$ \\
\hline Low risk group (> 45.5) & 1,732 & $226(13.0)$ & \\
\hline High risk group ( $\leq 45.5$ ) & 730 & $165(22.6)$ & \\
\hline Surgery approach & & & 0.175 \\
\hline Open & 1,743 & $288(16.5)$ & \\
\hline Laparoscopic & 719 & $103(14.3)$ & \\
\hline Tumor location & & & 0.125 \\
\hline Colon & 799 & $144(18.0)$ & \\
\hline Rectosigmoid & 1,658 & $246(14.8)$ & \\
\hline Both & 5 & $1(20.0)$ & \\
\hline Stage & & & 0.005 \\
\hline $0-1$ & 512 & 66 (12.9) & \\
\hline 2 & 703 & 116 (16.5) & \\
\hline 3 & 868 & $128(14.7)$ & \\
\hline 4 & 379 & 81 (21.4) & \\
\hline
\end{tabular}

ASA, American Society of Anesthesiologists; SNUH-NSI, Seoul National University Hospital-nutrition screening index; $\mathrm{PNI}$, prognostic nutritional index. plications. As a single complication, wound infection was the most frequent complication, which occurred in 46 subjects (1.9\%). Other single postoperative complications included intestinal obstruction in 43 patients (1.7\%), colonic stricture in $33(1.3 \%)$, pulmonary complications in $25(1.0 \%)$, and renal and urologic complications in $20(0.8 \%)$ (Table 4). The incidence of complications was significantly higher in the group at high than at low risk for malnutrition ( $25.5 \%$ vs. $13.9 \%, \mathrm{P}<0.001)$.

The relationship between the incidence of complications and risk of malnutrition differed, however, when the complications were classified as wound-related, operation-related, and systemic complications (Table 2). The incidence of wound-related complications was significantly higher in the group at high than at low risk for malnutrition (3.3\% vs. $1.6 \%, \mathrm{P}=0.016)$. However, the rates of operation-related complications ( $5.2 \%$ vs. $4.4 \%, \mathrm{P}=0.480)$ and systemic complications ( $3.3 \%$ vs. $2.0 \% \mathrm{P}=0.100$ ) did not differ significantly in the groups at high risk than at low risk of malnutrition.

\section{Factors affecting the occurrence of complications}

Univariate analysis showed that factors associated with a higher incidence of overall postoperative complications included a higher risk of malnutrition $(\mathrm{P}<0.001)$, male sex $(\mathrm{P}=0.001)$, a higher ASA score $(\mathrm{P}<0.001)$, palliative surgery $(\mathrm{P}=0.004)$, and higher clinical stage $(\mathrm{P}=0.004)$ (Table 5$)$. History of smoking, history of alcohol intake, operative method, and tumor location of tumors did not affect the incidence of overall complications. Multivariate analysis showed that a high risk for malnutrition according to both the SNUH-NSI score (odds ratio [OR], 1.868; 95\% confidence interval [CI], 1.429-2.442; $\mathrm{P}<0.001)$ and PNI score (OR, 1.596; 95\% CI, 1.258-2.025; P < 0.001), male sex (OR, 1.483; 95\% CI, 1.174-1.876; $\mathrm{P}=0.001)$, and a high ASA class (OR, 1.782; 95\% CI, 1.136-2.795; $\mathrm{P}=0.012$ ) were independent risk factors for the occurrence of complications (Table 6).

\section{DISCUSSION}

Surgery or trauma may increase catabolism and result in hypermetabolism, increasing protein and energy requirements [17]. This may lead to postoperative complications. Many factors have been associated with the occurrence of complications, including nutritional status $[4,18,19]$. Indeed, malnutrition has been reported in $30 \%-50 \%$ of patients who undergo gastrointestinal surgery [20]. Complications associated with nutritional status may prolong length of hospital stay and increase medical costs [21].

The present study provides additional evidence that nutritional status may affect surgical outcomes. This study found that the risk of malnutrition, in addition to low ASA class and sex, were factors 
Table 6. Multivariate analysis of risk factors for postoperative morbidity

\begin{tabular}{|c|c|c|c|c|}
\hline Variables & No. & P-value & Odds ratio & $95 \%$ Confidence interva \\
\hline \multicolumn{5}{|l|}{ SNUH-NSI } \\
\hline Low risk group & 2,039 & Reference & & \\
\hline High risk group & 423 & $<0.001$ & 1.868 & $1.429-2.442$ \\
\hline \multicolumn{5}{|l|}{ PNI } \\
\hline Low risk group (> 45.5) & 1,732 & Reference & 1.596 & $1.258-2.025$ \\
\hline High risk group ( $\leq 45.5$ ) & 730 & $<0.001$ & & \\
\hline \multicolumn{5}{|l|}{ Sex } \\
\hline Female & 962 & Reference & 1.483 & $1.174-1.876$ \\
\hline Male & 1,500 & 0.001 & & \\
\hline \multicolumn{5}{|l|}{ ASA class } \\
\hline 1,2 & 2,358 & Reference & 1.782 & $1.136-2.795$ \\
\hline 3,4 & 104 & 0.012 & & \\
\hline
\end{tabular}

SNUH-NSI, Seoul National University Hospital-nutrition screening index; PNI, prognostic nutritional index; ASA, American Society of Anesthesiologists.

affecting complications and contributed significantly to surgical outcomes.

Many attempts have been made to develop nutritional screening indices to assess patients' nutritional status. Serum albumin concentration has been the most commonly used single factor, with many studies suggesting that serum albumin level $<3.5 \mathrm{~g} / \mathrm{dL}$ is an independent risk factor for postoperative complications [22-24]. Because serum albumin has a relatively long half-life, and its concentration is highly affected by changes in non-nutritional factors, such as volume status or disease status, it may not accurately reflect recent nutritional status [22]. Other factors, such as serum total cholesterol concentration and total lymphocyte count, have been used to assess nutritional status in many clinical settings. However, these biochemical markers are also likely affected by factors other than nutritional status, limiting their individual value $[22,25,26]$.

To overcome the limitations of these single factors, various nutrition screening tools have been developed to assess patients' overall nutritional status [7]. These include the PNI, the Nutrition Risk Screening-2002 (NRS-2002), the Malnutrition Universal screening tool, the Mini Nutritional Assessment, the Short Nutritional Assessment Questionnaire, and the malnutrition screening tool (MST). The PNI was found to be a significant factor affecting postoperative outcomes in patients with colorectal cancer [11]. The NRS-2002 classifies nutritional status based on three factors, nutritional status based on BMI, weight loss and changes in intake; severity of disease by diagnosis; and age, with nutritional risk being a significant predictor of postoperative complications [4,9].

Although use of these screening tools may enable effective nutritional assessment, differences in the characteristics of patients between hospitals may result in differences in screening criteria that can sensitively reflect the risk of malnutrition. Some medical institutions have therefore developed their own nutritional screening tools and are making efforts to verify their validity. The SNUH has developed its own screening tool, the SNUH-NSI, to assess the nutritional status of patients [27]. The SNUH-NSI includes several parameters, including age; BMI; changes in body weight; appetite; digestive disorders and meal patterns at admission; serum concentrations of albumin, total cholesterol, and CRP; total lymphocyte counts, and hemoglobin level measured within 2 weeks before admission. In addition to measures of current weight, such as BMI, weight changes over time are recognized as important indices reflecting malnutrition $[13,14,22]$. Other factors included in the SNUH-NSI, such as appetite status, meal pattern and digestive symptoms, are also included in other nutritional assessment and screening tools, such as the Subjective Global Assessment (SGA), the Patient Generated-SGA (PG-SGA) and the NRS-2002. CRP is not a direct indicator of malnutrition, but is associated with inflammation and infection, which increase nutritional requirements. Elevated CRP is negatively associated with nutrition-related markers, such as prealbumin concentration, and has been reported to be an index associated with mortality of hospitalized patients [28]. The SNUH-NSI is a practical index for use in clinical settings with limited manpower and resources, because information on each parameter can be collected using an automatic screening system in the hospital. This tool can provide more specific information than a single parameter such as albumin concentration, and is relatively convenient to use compared with other nutritional assessment tools.

Other nutrition screening tools developed by individual medical institutions include the Gangnam Severance Hospital Nutritional Risk Screening Tool, the National Cancer Center Malnutrition Screening Tool for Cancer patients, and the Seoul National University Bundang Hospital nutrition screening index [7]. Both the SNUH-NSI and the NRS showed moderate agreement with the 
results of in-depth nutritional assessment using the PG-SGA, confirming that the SNUH-NSI and the NRS are suitable for use as nutrition screening tools [7].

Although many studies have assessed preoperative nutritional status in patients with cancers of the upper gastrointestinal tract and other organs, relatively few studies have analyzed preoperative nutritional status in patients with colorectal cancer. The present study used both the PNI and the SNUH-NSI to assess nutritional status, finding that these preoperative screening tools differed significantly in predicting complications, with the SNUH-NSI (OR, 1.868) being a stronger predictor of complications after colorectal cancer surgery than the PNI (OR, 1.596), indicating that the SNUH-NSI can be of value as a nutritional screening tool.

This study had several limitations, including its retrospective design and its inclusion of patients at a single institution. However, the number of patients was significantly larger compared with those of previous studies. In addition, it was difficult to determine the details of each operation that could affect postoperative complications. However, because they were elective surgeries, performed by experienced surgeons using standardized surgical procedures, these effects were regarded as not significant.

Despite these limitations, the use of nutritional screening tools to identify patients at risk of malnutrition may be clinically useful in predicting postoperative complications in patients with colorectal cancer. Nutritional screening tools such as the SNUH-NSI can be used to more easily predict complications in patients undergoing colorectal cancer surgery. As individualized and personalized health care is becoming more important these days, nutritional assessment of an individual by optimized tool will be useful.

The SNUH-NSI, a nutritional screening tool, based on blood test results, such as serum albumin and total cholesterol and hemoglobin concentrations, appetite, weight changes, dyspepsia, meal pattern, age and BMI at admission is an independent risk factor for complications in patients undergoing surgery for colorectal cancer. Preoperative nutritional screening may help predict postoperative complications and improve clinical prognosis. Further studies on more specific clinical effects are needed.

\section{CONFLICT OF INTEREST}

No potential conflict of interest relevant to this article was reported.

\section{ACKNOWLEDGMENTS}

This research was partly supported by Basic Science Research Program through the National Research Foundation of Korea (NRF) funded by the Ministry of Education (No. NRF2017R1D1A1B
03036191) and partly supported by supported by grant no. 042 0170600 (2017-1249) from the SNUH Research Fund.

\section{REFERENCES}

1. Brenner H, Kloor M, Pox CP. Colorectal cancer. Lancet 2014; 383:1490-502.

2. Winawer S, Fletcher R, Rex D, Bond J, Burt R, Ferrucci J, et al. Colorectal cancer screening and surveillance: clinical guidelines and rationale-Update based on new evidence. Gastroenterology 2003; 124:544-60.

3. Ryan AM, Power DG, Daly L, Cushen SJ, Ni Bhuachalla E, Prado CM. Cancer-associated malnutrition, cachexia and sarcopenia: the skeleton in the hospital closet 40 years later. Proc Nutr Soc 2016; 75:199-211.

4. Schwegler I, von Holzen A, Gutzwiller JP, Schlumpf R, Muhlebach S, Stanga Z. Nutritional risk is a clinical predictor of postoperative mortality and morbidity in surgery for colorectal cancer. Br J Surg 2010;97:92-7.

5. Cooper C, Brierley ER, Burden ST. Improving adherence to a care plan generated from the Malnutrition Universal Screening Tool. Eur J Clin Nutr 2013;67:174-9.

6. Weimann A, Braga M, Harsanyi L, Laviano A, Ljungqvist O, Soeters P, et al. ESPEN Guidelines on Enteral Nutrition: surgery including organ transplantation. Clin Nutr 2006;25:224-44.

7. Seol E, Ju DL, Lee HJ. Nutritional screening tool for in-hospital patients. J Clin Nutr 2016;8:2-10.

8. Hirashima K, Watanabe M, Shigaki H, Imamura Y, Ida S, Iwatsuki $\mathrm{M}$, et al. Prognostic significance of the modified Glasgow prognostic score in elderly patients with gastric cancer. J Gastroenterol 2014;49:1040-6.

9. Kwag SJ, Kim JG, Kang WK, Lee JK, Oh ST. The nutritional risk is a independent factor for postoperative morbidity in surgery for colorectal cancer. Ann Surg Treat Res 2014;86:206-11.

10. Watanabe $M$, Iwatsuki $M$, Iwagami S, Ishimoto T, Baba Y, Baba H. Prognostic nutritional index predicts outcomes of gastrectomy in the elderly. World J Surg 2012;36:1632-9.

11. Noh GT, Han J, Cho MS, Hur H, Min BS, Lee KY, et al. Impact of the prognostic nutritional index on the recovery and long-term oncologic outcome of patients with colorectal cancer. J Cancer Res Clin Oncol 2017;143:1235-42.

12. Kim Y, Kim WG, Lee HJ, Park MS, Lee YH, Cho JJ, et al. Impact of malnutrition risk determined by nutrition screening index on operative morbidity after gastric cancer surgery. J Korean Surg Soc 2011;80:1-9.

13. Lee RD, Nieman DC. Nutritional assessment. Maidenhead: McGraw-Hill Education; 2005. 
14. Charney P, Malone A, American Dietetic A. ADA pocket guide to nutrition assessment. Chicago: American Dietetic Association; 2009.

15. Kondrup J, Allison SP, Elia M, Vellas B, Plauth M. ESPEN guidelines for nutrition screening 2002. Clin Nutr 2003;22:415-21.

16. Kondrup J, Rasmussen HH, Hamberg O, Stanga Z. Nutritional risk screening (NRS 2002): a new method based on an analysis of controlled clinical trials. Clin Nutr 2003;22:321-36.

17. Hill AG, Hill GL. Metabolic response to severe injury. Br J Surg 1998;85:884-90.

18. Sungurtekin H, Sungurtekin U, Balci C, Zencir M, Erdem E. The influence of nutritional status on complications after major intraabdominal surgery. J Am Coll Nutr 2004;23:227-32.

19. Sorensen J, Kondrup J, Prokopowicz J, Schiesser M, Krahenbuhl L, Meier R, et al. EuroOOPS: an international, multicentre study to implement nutritional risk screening and evaluate clinical outcome. Clin Nutr 2008;27:340-9.

20. Schiesser M, Kirchhoff P, Muller MK, Schafer M, Clavien PA. The correlation of nutrition risk index, nutrition risk score, and bioimpedance analysis with postoperative complications in patients undergoing gastrointestinal surgery. Surgery 2009;145:519-26.

21. Shulkin DJ, Kinosian B, Glick H, Glen-Puschett C, Daly J, Eisenberg JM. The economic impact of infections: an analysis of hospital costs and charges in surgical patients with cancer. Arch Surg 1993;128:449-52.
22. Elliott L, Molseed LL, McCallum PD, American Dietetic A, Oncology Nutrition Dietetic Practice G. The clinical guide to oncology nutrition. Chicago, IL: American Dietetic Association; 2006.

23. Gibbs J, Cull W, Henderson W, Daley J, Hur K, Khuri SF. Preoperative serum albumin level as a predictor of operative mortality and morbidity: results from the National VA Surgical Risk Study. Arch Surg 1999;134:36-42.

24. Putwatana P, Reodecha P, Sirapo-ngam Y, Lertsithichai P, Sumboonnanonda K. Nutrition screening tools and the prediction of postoperative infectious and wound complications: comparison of methods in presence of risk adjustment. Nutrition 2005;21:691-7.

25. Oh CA, Kim DH, Oh SJ, Choi MG, Noh JH, Sohn TS, et al. Changes of the preoperative and postoperative nutritional statuses in patients with gastric cancer and assessment of the nutritional factors that are correlated with short-term postoperative complications. J Korean Gastric Cancer Assoc 2010;10:5-12.

26. Lee MS. Nutritional management in gastric cancer patients. J Korean Gastric Cancer Assoc 2003;3:172-7.

27. Kim Y, Kim WG, Lee HJ, Park MS, Lee YH, Kong SH, et al. Comparison of the impact of malnutrition by nutritional assessment and screening tools on operative morbidity after gastric cancer surgery. J Korean Soc Parenter Enter Nutr 2011;4:7-15.

28. Fein PA, Mittman N, Gadh R, Chattopadhyay J, Blaustein D, Mushnick R, et al. Malnutrition and inflammation in peritoneal dialysis patients. Kidney Int Suppl 2003;(87):S87-91. 